\title{
The cost of unresectable stage III or stage IV melanoma in Italy
}

\author{
Michele Maio ${ }^{1 *}$, Paolo Ascierto ${ }^{2}$, Alessandro Testori ${ }^{3}$, Ruggero Ridolfi ${ }^{4}$, Emilio Bajetta ${ }^{5}$, Paola Queirolo ${ }^{6}$, \\ Michele Guida ${ }^{7}$, Antonella Romanini ${ }^{8}$, Vanna Chiarion-Sileni ${ }^{9}$, Jacopo Pigozzo ${ }^{9}$, Anna Maria Di Giacomo ${ }^{1}$, \\ Mario Calandriello ${ }^{10}$, Guido Didoni ${ }^{10}$, Marck van Baardewijk ${ }^{11}$, Cyril Konto ${ }^{12}$ and Carlo Lucioni ${ }^{13}$
}

\begin{abstract}
Background: In recent decades, melanoma incidence has been increasing in European countries; in 2006, there were approximately 60,000 cases leading to 13,000 deaths. Within Europe there is some geographical variation in the incidence of melanoma, with the highest rates reported in Scandinavia (15 cases per 100,000 inhabitants per year) and the lowest in the Mediterranean countries (5 to 7 cases per 100,000 inhabitants per year).

Methods: The present article is based on the information collected in the MELODY study (MELanoma treatment patterns and Outcomes among patients with unresectable stage III or stage IV Disease: a retrospective longitudinal survey).

In that study, the medical charts of patients were reviewed to document current treatment patterns and to analyse information on patients, disease characteristics and healthcare resource utilization related to the treatment of advanced melanoma regarding patients who presented with a diagnosis of malignant melanoma (stage I to IV) at participating sites between 01 July, 2005 and 30 June, 2006.

Results: Summarizing, though the length of the follow-up period varies among sample patients, an amount of the yearly cost per patient can be estimated, dividing the average per patient total cost (€ 5.040) by the average follow-up duration (17.5 months) and reporting to one year; on these grounds, unresectable stage III or stage IV melanoma in Italy would cost € 3,456 per patient per year.
\end{abstract}

Keywords: Metastatic melanoma, Medical direct cost, Clinical outcomes

\section{Background}

In recent decades, melanoma incidence has been increasing in European countries; in 2006, there were approximately 60,000 cases leading to 13,000 deaths $[1,2]$.

Within Europe there is some geographical variation in the incidence of melanoma, with the highest rates reported in Scandinavia (15 cases per 100,000 inhabitants per year) and the lowest in the Mediterranean countries ( 5 to 7 cases per 100,000 inhabitants per year) $[3,4]$.

Risk factors for melanoma include family history of the disease, presence of multiple moles and a previous melanoma [5]. Epidemiological studies have shown acute

\footnotetext{
* Correspondence: mmaio@cro.it

${ }^{1}$ Medical Oncology and Immunotherapy, Azienda Ospedaliera Universitaria Senese, Istituto Toscano Tumori, Strada delle Scotte, 53100 Siena, Italy Full list of author information is available at the end of the article
}

and intermittent sunlight exposure is a major environmental etiological factor of malignant melanoma, but the evidence for the causative role of sunlight is still conflicting. Physical protection from exposure to sunlight is generally accepted as the most important factor of melanoma risk reduction. Active public education campaigns aimed at encouraging earlier detection of melanoma have led to the diagnosis of thinner lesions with a better prognosis [3,6].

Although melanoma accounts for only 4 percent of all skin cancers, it is responsible for 80 percent of deaths from this type of cancer and causes disproportionate mortality in patients of young and middle age [5,6]. Estimates of mortality rate from melanoma in Europe vary between 1.5 to 5.2 per 100,000 inhabitants per year [1].

More recent improvements in survival have been attributed in part to the earlier detection of melanoma.

\section{Biomed Central}

(c) 2012 Maio et al.; licensee BioMed Central Ltd. This is an Open Access article distributed under the terms of the Creative Commons Attribution License (http://creativecommons.org/licenses/by/2.0), which permits unrestricted use, distribution, and reproduction in any medium, provided the original work is properly cited. 
If the disease becomes metastatic, it is considered incurable. The prognosis for patients with distant metastasis remains bleak, with an estimated median survival of 6 to 10 months and less than 5 percent of patients surviving for more than 5 years [7].

Local recurrences of malignant melanoma and intransit metastasis are most effectively treated by surgical excision. Radiotherapy to bone or skin metastases can provide short term symptomatic control and offer palliative value, but patients in Europe with unresectable metastatic disease have very few systemic treatment options. Dacarbazine, an alkylating agent, is approved in Europe for the treatment of metastatic melanoma [6,8]. A number of other agents, including temozolomide and fotemustine, have been investigated for treatment of metastatic melanoma and because of their ability to cross the blood-brain barrier, may be used preferentially in melanoma patients with brain metastasis. However, no agent has been shown to improve survival rates. Immunotherapy with interleukin-2, approved by the FDA in the United States, did not receive approval for the treatment of metastatic melanoma in Europe. Little progress has been made in the medical treatment of metastatic melanoma in the last 3 decades [9].

The limited number of approved treatments for advanced melanoma patients suggests there is a high, unmet medical need for new therapies $[10,11]$.

\section{Methods}

In the development of new treatments, it is important to have an understanding of existing treatment options. In diseases such as advanced melanoma where few approved and effective treatment options exist, clinicians may adopt different approaches to manage patients' disease. Documenting and characterizing current treatments and their associated cost is important to define the dominant treatment practice and to quantify the impact of existing therapeutic strategies in terms of both clinical benefit for the patient, as well as cost to the healthcare system. Consequently the primary objective of this study is to document treatment patterns and evaluate relevant costs. In particular, to document firstline, second-line and beyond treatments types as well as the frequency with which they are used in patients diagnosed with unresectable stage III or stage IV melanoma.

The present article is based on the information collected in the MELODY study (MELanoma treatment patterns and Outcomes among patients with unresectable stage III or stage IV Disease: a retrospective longitudinal surve $\underline{Y}$ ).

In that study, the medical charts of patients were reviewed to document current treatment patterns and to analyse information on patients, disease characteristics and healthcare resource utilization related to the treatment of advanced melanoma. Moreover, the perspective of the Italian National Health System is adopted, so only direct costs are considered.

\section{The MELODY study}

The MELODY study was conducted as a multinational, observational retrospective longitudinal survey of patients diagnosed with unresectable stage III or stage IV melanoma. The target sample population was approximately 750 patients from 3 European countries: France, Italy and the United Kingdom. In each country 10 sites were selected, providing approximately 250 patients per country. In each participating site, consecutive patients with a diagnosis of malignant melanoma (stage III to IV) who presented at the site between 01 July 2005 and 30 June 2006 were entered into a registry where a limited set of parameters related to date and stage of disease was captured. Staging was in accordance with the American Joint Commission on Cancer (AJCC 2001) criteria [12]. Each site entered patients into the registry up to a maximum of 250 patients or until 25 eligible patients (those with a diagnosis of unresectable stage III or stage IV melanoma) were identified (whichever occurred first).

For each patient who met all inclusion criteria, medical chart data were abstracted beginning from the date of unresectable stage III or stage IV diagnosis until 01 May, 2008 or death, whichever occurred first. Given an estimated median survival of 6 to 10 months in the patient population, the duration of the follow-up from diagnosis until 01 May 2008 allowed an adequate time to collect information on treatments received, patient and disease characteristics, and health resource utilization. The patient identity (name, address and other identifiers) was not collected and ethics committee approval and patient informed consent were obtained.

Treatment data were collected by line of therapy. Data included systemic therapy (chemotherapy, immunotherapy), surgery, radiation, supportive care only, enrolment in a clinical trial or no treatment. For systemic therapy, name of the drug, schedule and method of administration, duration of treatment and reason for stopping treatment were collected. If a patient was enrolled in a clinical trial for treatment of advanced melanoma, the duration of the participation in the trial was noted in the case report form, but no further details (name of drug, schedule of administration) were collected.

\section{Healthcare resource utilization}

Categories of healthcare resource utilization included hospitalizations, outpatient visits, emergency department visits, hospice care, surgery, radiotherapy and management of adverse events (transfusions and concomitant medications including antiemetics and growth factors) 
related to the treatment of unresectable stage III or stage IV melanoma. Resource use related to treatments received as a part of a clinical trial was not reported.

In the MELODY study data were also collected on clinical benefits and outcomes of the treatments (response rate, disease control rate, time to response, duration of response and progression free survival). In this article only the response rate has been considered, in order to evaluate the level of costs per patient respectively responsive and non responsive to systemic therapy, stratifying by line and type of treatment.

Due to the anticipated small proportion of patients who receive second-line treatment and beyond, later lines of treatment were not characterized with the same level of precision as first-line treatments, hence caution should be applied in the interpretation of the findings regarding those lines. Loss to follow-up (including patients who stop treatment prematurely, transfer out of the treatment facility or death not documented in the patient's medical chart) is an inherent limitation of any retrospective study design. However, due to the short median duration of survival and to the frequent contacts between clinicians treating patients with advanced disease, loss to follow-up was low. For this reason, without compromising the sample size, only patients having a follow-up of $\geq 2$ months were included in the study, in order to minimize the number of patients whose melanoma was not treated or for whom no information on treatment was available.

\section{Database methodology and statistical analysis}

Patient and disease characteristics include patient age, gender, date and disease stage at first melanoma diagnosis, date and disease stage at advanced (stage III unresectable or stage IV) melanoma diagnosis (according to AJCC 2001 criteria) [12].

For each line of treatment (excluding treatments received as a part of a clinical trial), the number and duration of hospitalizations, the duration of hospice care, the number of outpatient visits and the number of emergency room visits related to the treatment of unresectable stage III or stage IV melanoma were recorded. Resource use associated with common adverse events (transfusion, administration of concomitant medications including antiemetics and growth factors) was recorded too.

Statistical analyses are predominantly descriptive in nature, presented as summary tables and including calculation of measures of central tendency and standard deviations for continuous variables and frequency distributions for categorical variables. The following analyses were performed on the sample data relative to the Italian patients.

\section{MELODY study: the Italian sub-study Stratification variables}

The population of interest included all patients in the participating Italian sites diagnosed with unresectable stage III or stage IV melanoma who received active treatment with systemic therapy, outside of a clinical

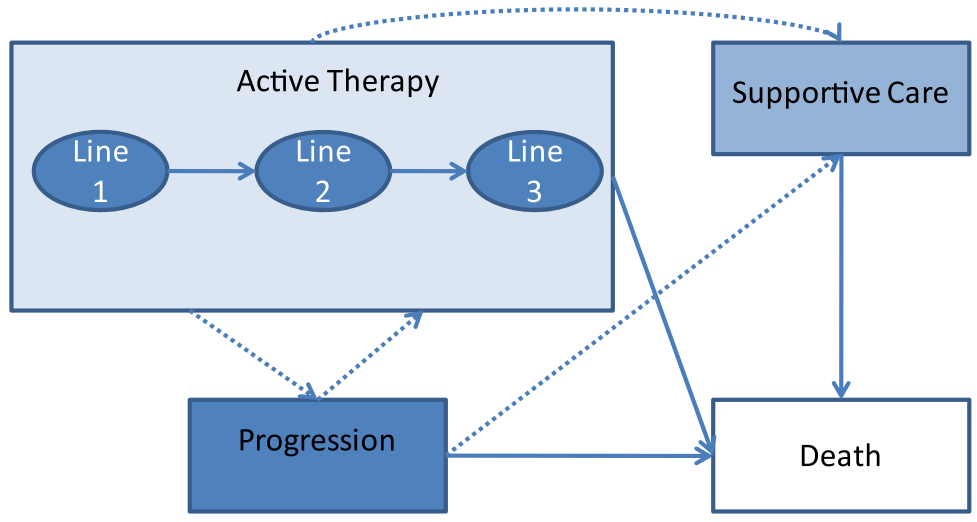

- Up to three lines of active therapy recorded per individual
- At any point, disease progression may occur
following progression
- From active therapy or progression, individuals can transition to
supportive care

Figure 1 Summary of potential patient pathways through treatment and health states in the MELODY study. 
trial, and/or any form of supportive care. Inclusion in this population varied across therapy lines, as shown in Figure 1. Up to three lines of active therapy were recorded per patient but, at any point of the treatment, disease progression might occur and some patients return to a subsequent line of active therapy following progression. From active therapy or progression, patients might move to supportive care, with the assumption of no return to active therapy following start of supportive care.

Within each line of therapy, all resource utilization variables were recorded for eligible patients receiving systemic therapy. Surgeries and radiotherapy were also recorded for patients receiving these therapies in combination with systemic therapy. If a patient switched from active therapy to supportive care, a subset of resource utilization variables were recorded (hospitalization, outpatient, emergency room, hospice care).

Within each line of active therapy, response was classified into five levels: complete response, partial response, stable disease, no response, and unable to determine. For the cost analyses at the therapy line level, different response status were grouped into two levels: any response (complete, partial, or stable disease) vs. no documented response (no response or unable to determine). For the cost analysis at the overall level, patients were classified as having any response if they had a documented response to any line of therapy, vs. no response if they did not have a documented response to any line of therapy.

Patient follow-up time was reported and used in calculating outcomes per unit time. Follow-up time was considered both overall and within lines of treatment and was calculated as follows:

- Overall follow-up time was defined as the length of time between first date of active therapy and last active date, where last active date is defined to be the date of last contact, death date, or censor date as appropriate for each patient.

- Follow-up time on a line of active therapy was defined as the difference between start date of the therapy and start date of next therapy for patients who went on to receive further active therapy or supportive care, or the difference between therapy start date and last

Table 1 Treatment of advanced melanoma in Italy - Unit costs

\begin{tabular}{|c|c|c|c|c|}
\hline Resource use item & Unit & Cost (€ 2009) & Notes & Source \\
\hline Hospitalization & cost per day & 740 & $\begin{array}{l}\text { Cost for one day stay in hospital, overall average. } \\
\text { Original data referred to } 2004 \text {, inflated to } \\
2009 \text { via consumer price index }\end{array}$ & [13] \\
\hline Hospice stay & cost per day & 211 & $\begin{array}{l}\text { Daily current tariff, mean of Lombardy } \\
\text { and Piedmont values }\end{array}$ & {$[14]$} \\
\hline Emergency room visit & cost per visit & 252 & $\begin{array}{l}\text { Original cost data referred to } 2007 \text {, } \\
\text { inflated to } 2009 \text { via consumer price index }\end{array}$ & {$[15]$} \\
\hline Outpatient (specialist visit) & cost per visit & 22 & Specialist visit, current tariff (code: 89.7 ) & {$[16]$} \\
\hline Adverse events (AE) & cost per day & see Note & $\begin{array}{l}\text { AEs classified into categories based on } \\
\text { ATC coding (level 2) of the drugs used } \\
\text { for their treatment. Daily drug cost based } \\
\text { on most frequently prescribed medications } \\
\text { (e.g. ondansetron, filgrastim, lenograstim, } \\
\text { pegfilgrastim, etc.) }\end{array}$ & {$[17]$} \\
\hline Radiotherapy & $\begin{array}{l}\text { cost per regimen in combination } \\
\text { with systemic therapy }\end{array}$ & 2814 & $\begin{array}{l}\text { DRG } 409 \text { (radiotherapy in day hospital) } \\
\text { current tariff times average } \\
\text { radiotherapies/patient number (7.5) }\end{array}$ & {$[18,19]$} \\
\hline Transfusion & cost per procedure & 179 & $\begin{array}{l}\text { Current tariff for one unit ( } \mathrm{ml} 280+/-20 \% \text { ) } \\
\text { of red blood cells added to transfusion } \\
\text { procedure tariff (code: } 99.07 .1 \text { ) }\end{array}$ & {$[16,20]$} \\
\hline \multicolumn{5}{|l|}{ SURGERY } \\
\hline Resection of primary tumor & cost per procedure & 2785 & DRG 266 tariff & \\
\hline Lymph node resection & cost per procedure & 1359 & DRG 270 tariff & {$[18]$} \\
\hline All other visceral & cost per procedure & 7322 & $\begin{array}{l}\text { Average of DRG tariffs (192: liver } \\
\text { and pancreas; 149: abdomen; 303: kidney) }\end{array}$ & {$[18]$} \\
\hline Brain metastases & cost per procedure & 13493 & DRG 001 tariff & {$[18]$} \\
\hline Isolated limb perfusion & cost per procedure & 2411 & DRG 273 tariff & {$[18]$} \\
\hline Biopsy & cost per procedure & 14 & Procedure tariff (code: 86.11) & {$[16]$} \\
\hline Distant skin & cost per procedure & 2072 & Average of DRG 266 and 270 tariffs & {$[18]$} \\
\hline Lung & cost per procedure & 8335 & DRG 75 tariff & [18] \\
\hline
\end{tabular}


contact date for patients who did not receive any further therapy.

\section{Sample profile}

The total number of patients was stratified in three lines of active therapy plus supportive care. At the end of the follow-up, the same patient might have been included in more than one line of therapy (due to successively moving from one to another).

\section{Outcome variables stratification}

All outcomes relating to intensity of resource utilization were stratified by line of therapy and by response rate. Due to low outcome rates, for hospice care, emergency room visits and transfusion, no stratification was considered. For adverse events the only stratification considered was per line of therapy, as response status is not of interest with respect to adverse events. Medication use was adopted as a proxy for adverse events incidence and duration.

\section{Italian unit costs}

Table 1 shows unit costs for Italy in 2009 euro values. Unit costs were obtained from several sources (when available, from published microcosting analysis or from published articles). When real costs were not available, current tariffs (mainly DRG ones) were used as a proxy. The costs of medical management agents for adverse events were calculated using an algorithm where adverse events were classified into categories based on ATC (Anatomical Therapeutic Chemical - level 2) of the drugs used for their treatment. Daily drug cost was based on most frequently prescribed medication. When necessary, original cost data were inflated to 2009 via consumer price index. More detailed information on unit cost can be found on notes included in Table 1, and in relevant references there quoted.

\section{Results}

\section{Characteristics of the study sample}

Table 2 reports descriptive statistics of the sub-study sample. The sample included 215 patients, who were eligible to contribute resource utilization data having received active therapy only (191), active therapy and supportive care (17) and supportive care without prior resource utilization (7). Moreover, 147 received first- line therapy, 112 second-line therapy and 41 third-line therapy (Figure 2). Stratification per line of active therapy considered 300 therapeutic treatments, a larger number than the total of patients receiving active therapy (208), because the same patient might have received more than one line of therapy.

The different major therapy options used are: 33\% first line patients were treated with dacarbazine, $20 \%$ with
Table 2 Descriptive statistics of study sample

\begin{tabular}{|c|c|c|}
\hline \multirow{3}{*}{ Age at diagnosis (years) } & \multicolumn{2}{|c|}{ Italy population $(\mathrm{N}=215)$} \\
\hline & Mean & SD \\
\hline & 55 & 13,9 \\
\hline Sex & $\mathrm{N}$ & $\%$ \\
\hline Male & 135 & $62,9 \%$ \\
\hline Female & 80 & $37,1 \%$ \\
\hline $\begin{array}{l}\text { Total receiving active } \\
\text { systemic therapy }\end{array}$ & $\mathrm{N}$ & $\%$ \\
\hline Overall & 208 & $96,7 \%$ \\
\hline First-line & 147 & $68,4 \%$ \\
\hline Second-line & 112 & $52,1 \%$ \\
\hline Third-line & 41 & $19,1 \%$ \\
\hline \multicolumn{3}{|l|}{ of which: } \\
\hline $\begin{array}{l}\text { any response to } \\
\text { systematic therapy }\end{array}$ & $\mathrm{N}$ & $\%$ \\
\hline Overall & 89 & $42,8 \%$ \\
\hline First-line & 53 & $36,1 \%$ \\
\hline Second-line & 34 & $30,4 \%$ \\
\hline Third-line & 14 & $34,1 \%$ \\
\hline Total follow-up time (months) & Mean & SD \\
\hline Overall & 17,5 & 13 \\
\hline First-line & 9,9 & 10,7 \\
\hline Second-line & 8,9 & 7,7 \\
\hline Third-line & 7,7 & 6,7 \\
\hline Supportive care & 4,9 & 5 \\
\hline Received supportive care & $\mathrm{N}$ & $\%$ \\
\hline Total & 24 & $11,2 \%$ \\
\hline $\begin{array}{l}\text { with at least one line of } \\
\text { active systematic therapy }\end{array}$ & 17 & $7,9 \%$ \\
\hline
\end{tabular}

fotemustine, and $12 \%$ with a combination of dacarbazine + fotemustine; in second line, $51 \%$ of patients were treated with fotemustine, and $10 \%$ with dacarbazine; in third line, fotemustine was used for $40 \%$ of patients, while dacarbazine for $8 \%$ of patients.

The mean age at the diagnosis was 55 years and male patients represented $62.9 \%$ of the sample. Among the 300 therapeutic treatments $42.8 \%$ showed some response to systemic therapy. Within each line of therapy - that is net of double counting - response rate was lower (36.1\% in the first line, $30.4 \%$ in the second line and 34.1 in the third line).

The total length of follow-up time was 17.5 months, with lower durations in the first line (9.9 months) in the second line (8.9 months) and in the third line (4.9 months).

\section{Hospitalization}

Hospitalizations were not particularly frequent, with less than $10 \%$ of all patients experiencing it. Hospitalization tended to be more frequent $(12.4 \%$ vs $5.9 \%)$ for patients 


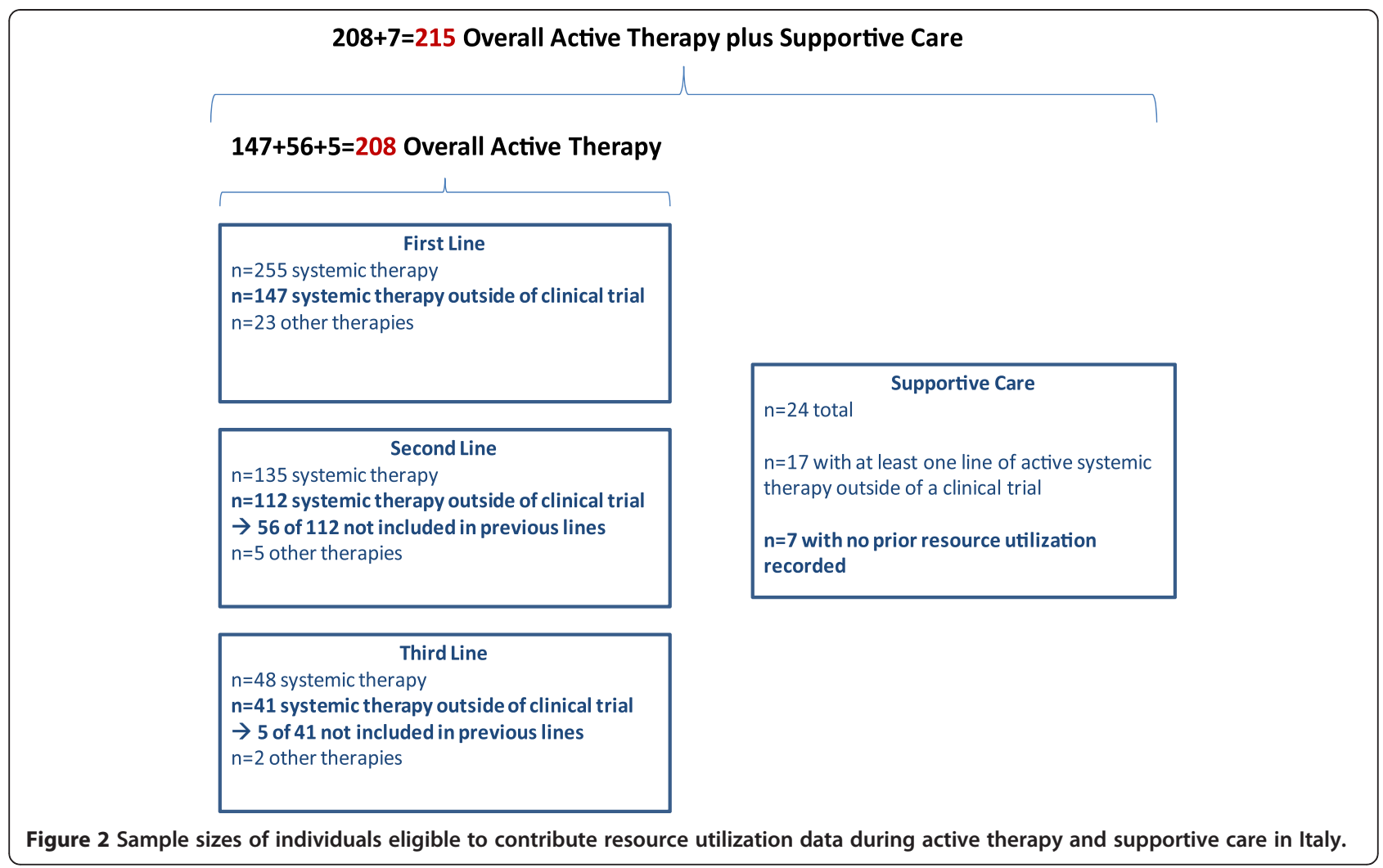

with any response to systemic therapy in comparison with those with no response (Table 3 , Table 4 and Table 5). Hospitalization was the most expensive category of resource utilisation, both among those who experienced hospitalization (mean total cost of $€ 25,540$ ) and with reference to the generality of the sample (i.e. including patients with zero utilisation): $€ 2,481$. Moreover, the mean cost per patient with any response to systemic therapy was higher than the mean cost per patient with no response $(€ 4,524$ vs $€ 882)$; the mean cost per patient in the first line of therapy $(€ 2,634)$ was higher than the overall cost $(€ 2,481)$, and much higher than the mean cost per patient in the second $(€ 588)$ and third $(€ 1.356)$ line of therapy.

As previously pointed out, the same patient might be included in more than one sub-set (first-line, secondline and third-line). But this event raises perplexities when making comparisons, with discrepancies that are

Table 3 Summary statistics for hospitalizations for patients receiving systemic therapy and/or supportive care

\begin{tabular}{|c|c|c|c|c|c|c|}
\hline & & Overall & First-line therapy & $\begin{array}{l}\text { Second-line } \\
\text { therapy }\end{array}$ & $\begin{array}{l}\text { Third-line } \\
\text { therapy }\end{array}$ & $\begin{array}{l}\text { Supportive } \\
\text { care }\end{array}$ \\
\hline $\mathrm{N}$ & & 215 & 147 & 112 & 41 & 24 \\
\hline \multirow[t]{2}{*}{ Patients with any hospitalization } & $\mathrm{N}$ & 21 & 11 & 7 & 4 & 4 \\
\hline & $\%$ & $9,8 \%$ & $7,5 \%$ & $6,3 \%$ & $9,8 \%$ & $16,7 \%$ \\
\hline \multirow[t]{2}{*}{ Total length of hospitalization (days) } & Mean & 34,3 & 47,5 & 12,7 & 18,8 & 8,2 \\
\hline & $95 \% \mathrm{Cl}$ & $0-73,7$ & $0-126,6$ & $6,6-18,8$ & $0-38,9$ & $1,1-15,4$ \\
\hline \multirow[t]{2}{*}{ Length of hospitalization (days/month ${ }^{(1)}$ ) } & Mean & 1,9 & 11,6 & 6,1 & 7,5 & 19,8 \\
\hline & $95 \% \mathrm{Cl}$ & $0,6-3,2$ & $0-30,8$ & $0-15,3$ & $0-27,4$ & $0-74,2$ \\
\hline \multirow{2}{*}{$\begin{array}{l}\text { Total hospitalization cost } \\
\text { per hospitalized patient ( } € \text { 2009) }\end{array}$} & Mean & 25.400 & 35.200 & 9.400 & 13.900 & 6.100 \\
\hline & $95 \% \mathrm{Cl}$ & $0-54.500$ & $0-93.700$ & $4.900-13.900$ & $0-28.800$ & $800-11.400$ \\
\hline \multirow{2}{*}{$\begin{array}{l}\text { Total hospitalization cost } \\
\text { per hospitalized patient per month (€ 2009) }\end{array}$} & Mean & 1.400 & 8.600 & 4.500 & 5.600 & 14.700 \\
\hline & $95 \% \mathrm{Cl}$ & $400-2.400$ & $0-22.800$ & $0-11.300$ & $0-20.300$ & $0-54.900$ \\
\hline Total hospitalization cost per patient (€ 2009) & Mean & 2.481 & 2.634 & 588 & 1.356 & 1.017 \\
\hline
\end{tabular}


Table 4 Summary statistics for hospitalizations for patients with any response to systemic therapy

\begin{tabular}{|c|c|c|c|c|c|}
\hline & & Overall & First-line therapy & Second-line therapy & Third-line therapy \\
\hline$\overline{\mathrm{N}}$ & & 89 & 53 & 34 & 14 \\
\hline \multirow[t]{2}{*}{ Patients with any hospitalization } & $\mathrm{N}$ & 11 & 5 & 4 & 1 \\
\hline & $\overline{\%}$ & $12,4 \%$ & $9,4 \%$ & $11,8 \%$ & $7,1 \%$ \\
\hline \multirow[t]{2}{*}{ Total length of hospitalization (days) } & Mean & 49,5 & 13,4 & 10,5 & 16 \\
\hline & $95 \% \mathrm{Cl}$ & $0-129,9$ & $2,2-24,6$ & $0,6-20,4$ & NA \\
\hline \multirow[t]{2}{*}{ Length of hospitalization (days/month ${ }^{(1)}$ ) } & Mean & 3 & 3,3 & 1,2 & 1,4 \\
\hline & $95 \% \mathrm{Cl}$ & $1,4-4,6$ & $0,9-5,8$ & $0,6-1,8$ & $1,4-1,4$ \\
\hline \multirow{2}{*}{$\begin{array}{l}\text { Total hospitalization cost } \\
\text { per hospitalized patient (€ 2009) }\end{array}$} & Mean & 36.600 & 9.900 & 7.770 & 11.800 \\
\hline & $95 \% \mathrm{Cl}$ & $0-96.100$ & $1.600-18.200$ & $400-15.100$ & NA \\
\hline \multirow{2}{*}{$\begin{array}{l}\text { Total hospitalization cost } \\
\text { per hospitalized patient per month }(€ 2009)\end{array}$} & Mean & 2.200 & 2.400 & 888 & 1.000 \\
\hline & $95 \% \mathrm{Cl}$ & $1.000-3.400$ & $700-4.300$ & $400-1.300$ & $1.000-1.000$ \\
\hline Total hospitalization cost per patient (€ 2009) & Mean & 4.524 & 934 & 914 & 843 \\
\hline
\end{tabular}

particularly evident when results are analysed separately for patients with any response to systemic therapy and with no response to systemic therapy (Tables 4 and Table 5). For example, the overall mean length of stay does not correspond to the mean of the line-specific length of stay in Table 4 ("Any response to therapy"). This is due to the definition of responders. Within each line of therapy, patients are classified as responders or non-responders, and their results are included in the corresponding table. For the Overall column, a patient is included in the "Any Response" table if he/she did ever respond to a single line of therapy, and is included in the "No Response" table if he/she never did. So, considering a hypothetical patient who responded to first-line therapy but not to second-line or third-line therapy, he would be included in the Overall column and in the first-line column in Table 4 (since he did respond to this line of therapy); and he would be included in the second- and third-line columns in Table 5 (because he did not respond to these lines of therapy). Consequently
Overall columns in Table 4 (and analogously in Table 5) do not correspond to an average of the line-specific columns because patients can move across tables ${ }^{\mathrm{a}}$.

These methodological considerations are done here to justify why results will not be commented separately per single line of treatment, when patients are analyzed with any/no response to systemic therapy.

Summarizing, though the length of the follow-up period varies among sample patients, an amount of the yearly cost per patient can be estimated, dividing the average per patient total cost $(€ 5.040)$ by the average follow-up duration (17.5 months) and reporting to one year; on these grounds, unresectable stage III or stage IV melanoma in Italy would cost $€ 3,456$ per patient per year.

\section{Hospice care}

Approximately $6 \%$ of patients received hospice care with a mean cost per admitted patient of $€ 3.300$. Due to the

Table 5 Summary statistics for hospitalizations for patients with no response to systemic therapy

\begin{tabular}{|c|c|c|c|c|c|}
\hline & & Overall & First-line therapy & Second-line therapy & Third-line therapy \\
\hline $\mathrm{N}$ & & 119 & 94 & 78 & 27 \\
\hline \multirow[t]{2}{*}{ Patients with any hospitalization } & $\mathrm{N}$ & 7 & 6 & 3 & 3 \\
\hline & $\%$ & $5,9 \%$ & $6,4 \%$ & $3,8 \%$ & $11,1 \%$ \\
\hline \multirow[t]{2}{*}{ Total length of hospitalization (days) } & Mean & 20,3 & 76 & 15,7 & 19,7 \\
\hline & $95 \% \mathrm{Cl}$ & $10,5-30,1$ & $0-243,6$ & $0-33,3$ & $0-57,7$ \\
\hline \multirow[t]{2}{*}{ Length of hospitalization (days/month ${ }^{(1)}$ ) } & Mean & 2,5 & 18 & 10,9 & 7,4 \\
\hline & $95 \% \mathrm{Cl}$ & $1,9-3$ & $0-39,3$ & $2-19,8$ & $0-17,1$ \\
\hline \multirow{2}{*}{$\begin{array}{l}\text { Total hospitalization cost } \\
\text { per hospitalized patient ( } € \text { 2009) }\end{array}$} & Mean & 15.000 & 56.200 & 11.600 & 14.600 \\
\hline & $95 \% \mathrm{Cl}$ & $7.800-22.300$ & $0-180.300$ & $0-24.600$ & $0-42.700$ \\
\hline \multirow{2}{*}{$\begin{array}{l}\text { Total hospitalization cost } \\
\text { per hospitalized patient per month ( } € 2009 \text { ) }\end{array}$} & Mean & 1.900 & 13.300 & 8.100 & 5.500 \\
\hline & $95 \% \mathrm{Cl}$ & $1.400-2.200$ & $0-29.100$ & $1.500-14.700$ & $0-12.700$ \\
\hline Total hospitalization cost per patient (€ 2009) & Mean & 882 & 3.587 & 446 & 1.622 \\
\hline
\end{tabular}


Table 6 Summary statistics for outpatient visits for patients receiving systemic therapy and/or supportive care

\begin{tabular}{|c|c|c|c|c|c|c|}
\hline & & Overall & First-line therapy & Second-line therapy & Third-line therapy & Supportive care \\
\hline $\mathrm{N}$ & & 215 & 147 & 112 & 41 & 24 \\
\hline \multirow[t]{2}{*}{ Patients with any outpatient visits } & $\mathrm{N}$ & 87 & 44 & 36 & 19 & 15 \\
\hline & $\%$ & $40,5 \%$ & $29,9 \%$ & $32,1 \%$ & $46,3 \%$ & $62,5 \%$ \\
\hline \multirow{2}{*}{$\begin{array}{l}\text { Total number of outpatient visits } \\
\text { per visited patient }\end{array}$} & Mean & 3,3 & 2,4 & 2,5 & 2,5 & 2,7 \\
\hline & $95 \% \mathrm{Cl}$ & $2,8-3,7$ & $2,1-2,8$ & $2-3$ & $1,8-3,2$ & $1,9-3,4$ \\
\hline \multirow{2}{*}{$\begin{array}{l}\text { Total number of outpatient visits } \\
\text { per visited patient per month }{ }^{(1)}\end{array}$} & Mean & 0,3 & 0,5 & 0,6 & 0,5 & 3,3 \\
\hline & $95 \% \mathrm{Cl}$ & $0,2-0,4$ & $0,3-0,7$ & $0,3-0,9$ & $0,4-0,7$ & $0-7,1$ \\
\hline \multirow{2}{*}{$\begin{array}{l}\text { Total outpatient cost } \\
\text { per visited patient }(€ 2009)\end{array}$} & Mean & 70 & 50 & 60 & 50 & 60 \\
\hline & $95 \% \mathrm{Cl}$ & $60-80$ & $50-60$ & $40-70$ & $40-70$ & $40-80$ \\
\hline \multirow{2}{*}{$\begin{array}{l}\text { Total outpatient cost } \\
\text { per visited patient per month ( } € \text { 2009) }\end{array}$} & Mean & 7 & 11 & 13 & 11 & 73 \\
\hline & $95 \% \mathrm{Cl}$ & $4-9$ & $7-15$ & $7-20$ & $9-15$ & $0-156$ \\
\hline Total outpatient cost per patient (€ 2009) & Mean & 28 & 15 & 19 & 23 & 38 \\
\hline
\end{tabular}

low frequency of such resource use, the mean cost for the generality of the sample is quite low ( $€ 184)$.

\section{Emergency room visit}

Emergency room visits were very rare: overall $1.4 \%$ of patients had one or more visit. Consequently the mean cost for the generality of the sample is very low $(€ 4)$.

\section{Outpatient visit}

Outpatient visits were the most common category of resource utilization: $40.5 \%$ of patients had at least one visit, with 3.3 visits per patient (Overall) on average. As compared with other major categories of utilization, outpatient visits were relatively inexpensive, with a mean cost of $€ 70$ per visited patient and a mean cost for the generality of the sample of $€ 28$ (Table 6). Outpatient visits were more frequent in patients with any response to systemic therapy, where the mean cost per patient was higher than the mean cost per non responder patient ( $€ 33$ vs $€ 22$ ).

\section{Adverse events}

On the whole, $24 \%$ of patients received medications to manage one or more adverse events (AE). Most of the patients experienced just one $\mathrm{AE}$ requiring medical management. The most frequent category of AE medical management agent was antiemetics and antinauseants, the most expensive category of medication was immunostimulants, ranging from $€ 785$ to $€ 3,051$ per episode (Table 7).

\section{Radiotherapy}

Among patients who received systemic therapy, 19.7\% received radiotherapy in combination (Tables 8 and 9). Radiotherapy costs were based on standard protocols regimens. Mean cost per patient receiving radiotherapy was equal to the unit cost of this resource ( $€$ 2.814).

Table 7 Cost of adverse event management for most commonly prescribed agents (occurring in $\geq 5 \%$ of patients

\begin{tabular}{|c|c|c|c|c|c|}
\hline $\begin{array}{l}\text { Category of adverse event } \\
\text { management }\end{array}$ & $\begin{array}{l}\text { Most frequent } \\
\text { medical agent(s) }\end{array}$ & $\begin{array}{l}\text { Percentage of events } \\
\text { treated with agent }\end{array}$ & $\begin{array}{l}\text { Unit cost per day } \\
(€ 2009)\end{array}$ & $\begin{array}{l}\text { Mean duration } \\
\text { (days) }\end{array}$ & $\begin{array}{l}\text { Cost per event } \\
(€ 2009)\end{array}$ \\
\hline Antiemetics and antinauseants & Ondansetron (1), (2) & 90,7 & 5,99 & 66,5 & 56,9 \\
\hline Drugs for acid related disorders & Omeprazole & 75 & 0,25 & 99,5 & 24,9 \\
\hline Corticosteroids for systemic use & Dexamethasone & 50 & 0,8 & 133,3 & 106,6 \\
\hline \multirow[t]{2}{*}{ Analgesics } & Co-efferalgan & 30,8 & 0,52 & 48,5 & 25,2 \\
\hline & Tramadol & 30,8 & 1,92 & 25,5 & 49 \\
\hline $\begin{array}{l}\text { Drugs for functional } \\
\text { gastrointestinal disorders }\end{array}$ & Metoclopramide & 100 & 0,92 & 97,5 & 89,7 \\
\hline \multirow[t]{3}{*}{ Immunostimulants } & Filgrastim $^{(3)}$ & 44,4 & 65,42 & 23,2 & 785 \\
\hline & Lenograstim & 11,1 & 79,39 & 12 & 952,7 \\
\hline & Pegfilgrastim & 11,1 & 902,48 & 71 & 3051,2 \\
\hline
\end{tabular}

\footnotetext{
(1) Assumed maximum duration 3 days per 21-day cycle throughout observed mean duration.

(2) Unit cost is per day, given once per 21-day cycle throughout observed mean duration.

(3) Assumed maximum duration 12 days; if observed mean duration of 23,2 days is used, then total cost is 1517,7 .

(4) Unit cost is per cycle, given once per 21-day cycle throughout observed mean duration.
} 
Table 8 Summary statistics for radiotherapy for patients receiving systemic therapy

\begin{tabular}{|c|c|c|c|c|c|}
\hline & & Overall & First-line therapy & Second-line therapy & Third-line therapy \\
\hline $\mathrm{N}$ & & 208 & 147 & 112 & 41 \\
\hline \multirow[t]{2}{*}{ Patients with any radiotherapy } & $\mathrm{N}$ & 41 & 24 & 13 & 6 \\
\hline & $\%$ & $19,7 \%$ & $16,3 \%$ & $11,6 \%$ & $14,6 \%$ \\
\hline \multirow{2}{*}{$\begin{array}{l}\text { Incidence of radiotherapy } \\
\text { (per patient with any radiotherapy per month }{ }^{(1)} \text { ) }\end{array}$} & Mean & 0,1 & 0,31 & 0,27 & 0,14 \\
\hline & $95 \% \mathrm{Cl}$ & $0,08-0,13$ & $0,13-0,5$ & $0,07-0,46$ & $0,03-0,24$ \\
\hline $\begin{array}{l}\text { Total radiotherapy cost } \\
\text { per patient with any radiotherapy (€ 2009) }\end{array}$ & Mean & 2.814 & 2.814 & 2.814 & 2.814 \\
\hline \multirow{2}{*}{$\begin{array}{l}\text { Total radiotherapy cost } \\
\text { per patient with any radiotherapy per month }(€ 2009)\end{array}$} & Mean & 300 & 900 & 800 & 400 \\
\hline & $95 \% \mathrm{Cl}$ & $200-400$ & $400-1.400$ & $200-1.300$ & $100-700$ \\
\hline Total radiotherapy cost per patient $(€ 2009)$ & Mean & 555 & 459 & 327 & 412 \\
\hline
\end{tabular}

${ }^{(1)}$ month of follow-up.

Mean cost per patient for the generality of the sample resulted equal to $€ 555$. Small differences in mean cost per patient with any response $(€ 506)$ vs no response $(€ 591)$ are due to the different frequency in the resource use (18.05\% vs $21 \%)$.

\section{Transfusion}

Transfusions were relatively rare, with $3.8 \%$ of all patients who received systemic therapy also receiving a transfusion. Consequently the mean cost for the generality of the sample is very low (€ 12$)$.

\section{Surgery}

$24 \%$ of patients received surgery in combination with systemic therapy (Table 10). Surgery was more common in patients who had any response to systemic therapy $(30.35 \%)$ as compared with those with no response $(19,3 \%)$ (Tables 11 and 12). Surgery was among the most expensive categories of resource utilization, with a mean cost of $€ 7,390$ per patient with any surgery. With reference to the generality of the sample, mean cost per patient with any response was equal to $€ 2,312$, which is higher than the cost per patient with no response (€ 1.376).

\section{Conclusions}

In the MELODY study data on resource use is collected based on patients stratification accordingly to treatment line, which implies that a given patient may be included in more than one line. This is the reason why in the present article costs per line are not examined, since the balancing cannot be found between the mean cost of the whole sample and the weighted mean cost of the strata. Instead, (Overall) costs are considered within two strata (patients with any/no response to systemic therapy) since the number of patients considered therein is stable within the different cost categories, so that the weighted mean cost of the two strata approximates the mean cost of the whole sample.

Moreover, it has to be noted that the reference period for calculating resource consumption by each patient corresponds to the follow-up period, which varies among patients. Therefore, the mean cost per patient is not directly referred to a standard time period (e.g. one year).

The following summary data must be appraised in the light of the above considerations, bearing in mind that the follow-up period is 17.5 months long on the average (Table 2) and that the balancing is rough between the mean cost of the whole sample and the weighted mean

Table 9 Summary statistics for radiotherapy for patients with any response to systemic therapy

\begin{tabular}{|c|c|c|c|c|c|}
\hline & & Overall & First-line therapy & Second-line therapy & Third-line therapy \\
\hline $\mathrm{N}$ & & 89 & 53 & 34 & 14 \\
\hline \multirow[t]{2}{*}{ Patients with any radiotherapy } & $\mathrm{N}$ & 16 & 7 & 3 & 3 \\
\hline & $\%$ & $18,0 \%$ & $13,2 \%$ & $8,8 \%$ & $21,4 \%$ \\
\hline \multirow{2}{*}{$\begin{array}{l}\text { Incidence of radiotherapy } \\
\text { (per patient with any radiotherapy per month }{ }^{(1)} \text { ) }\end{array}$} & Mean & 0,06 & 0,17 & 0,07 & 0,17 \\
\hline & $95 \% \mathrm{Cl}$ & $0,04-0,08$ & $0,09-0,25$ & $0,05-0,1$ & $0,-0,4$ \\
\hline $\begin{array}{l}\text { Total radiotherapy cost } \\
\text { per patient with any radiotherapy (€ 2009) }\end{array}$ & Mean & 2.814 & 2.814 & 2.814 & 2.814 \\
\hline \multirow{2}{*}{$\begin{array}{l}\text { Total radiotherapy cost } \\
\text { per patient with any radiotherapy per month ( } € 2009)\end{array}$} & Mean & 200 & 500 & 200 & 500 \\
\hline & $95 \% \mathrm{Cl}$ & $100-200$ & $300-700$ & $100-300$ & $0-1.100$ \\
\hline Total radiotherapy cost per patient (€ 2009) & Mean & 506 & 372 & 248 & 603 \\
\hline
\end{tabular}


Table 10 Summary statistics for surgery for patients receiving systemic therapy

\begin{tabular}{|c|c|c|c|c|c|}
\hline & & Overall & First-line therapy & Second-line therapy & Third-line therapy \\
\hline $\mathrm{N}$ & & 208 & 147 & 112 & 41 \\
\hline \multirow[t]{2}{*}{ Patients with any surgery } & $\mathrm{N}$ & 50 & 36 & 18 & 5 \\
\hline & $\%$ & $24,0 \%$ & $24,5 \%$ & $16,1 \%$ & $12,2 \%$ \\
\hline \multicolumn{6}{|l|}{ Type of surgery } \\
\hline Resection of primary tumor & $\%$ & $9 \%$ & $9 \%$ & $0 \%$ & $0 \%$ \\
\hline Lymph node resection & $\%$ & $21 \%$ & $16 \%$ & $3 \%$ & $2 \%$ \\
\hline All other visceral & $\%$ & $22 \%$ & $12 \%$ & $7 \%$ & $3 \%$ \\
\hline Brain metastases & $\%$ & $9 \%$ & $5 \%$ & $3 \%$ & $1 \%$ \\
\hline Isolated limb perfusion & $\%$ & $0 \%$ & $0 \%$ & $0 \%$ & $0 \%$ \\
\hline Biopsy & $\%$ & $12 \%$ & $9 \%$ & $2 \%$ & $1 \%$ \\
\hline Distant skin, subcutaneous or node & $\%$ & $12 \%$ & $9 \%$ & $3 \%$ & $0 \%$ \\
\hline Lung & $\%$ & $1 \%$ & $1 \%$ & $0 \%$ & $0 \%$ \\
\hline $\begin{array}{l}\text { Total surgery cost } \\
\text { per patient with any surgery (€ 2009) }\end{array}$ & Mean & 7.390 & 6.368 & 5.670 & 7.638 \\
\hline Total surgery cost per patient $(€ 2009)$ & Mean & 1.776 & 1.560 & 911 & 931 \\
\hline
\end{tabular}

cost calculated on the two strata (any/no response) (Table 13).

The mean cost per patient for the generality of the sample is $€ 5,040$. Hospitalisation is responsible for one half $(49.2 \%)$ of it and surgery for more than one third (35.2\%), so that both categories take up about $85 \%$ of the total amount. Radiotherapy is the third relevant category $(10 \%)$. Of the remaining ones, only hospice is non negligible.

On the whole, these resources are supplied in a specialistic environment, for which hospitalization of patient is required. Only visits can be performed in outpatient setting.

The cost composition is emphasized in the former of the two strata considered (patients with any response to systemic therapy): hospitalization (59.7\%) and surgery (30.5\%) take up more than $90 \%$ of the cost for resources. Among patients with no response, instead, both categories together take up only $73.5 \%$, where - on the other hand - hospitalization decreases to $28.7 \%$ but surgery increases to $44 \%$; in this stratum the share for radiotherapy too is high $(19.2 \%)$, when compared with the analogous in the former stratum (6.7\%). Considering, moreover, that patients with any response cost on the average two and a half times compared to patients with no response $(€ 7,575$ vs $€ 3,071)$, one can infer that treatment profiles are remarkably different: in the former stratum hospitalization (where chemotherapy is administered) is prevailing, while in the latter surgery and radiotherapy come first.

Table 11 Summary statistics for surgery for patients with any response to systemic therapy

\begin{tabular}{|c|c|c|c|c|c|}
\hline & & Overall & First-line therapy & Second-line therapy & Third-line therapy \\
\hline $\bar{N}$ & & 89 & 53 & 34 & 14 \\
\hline \multirow[t]{2}{*}{ Patients with any surgery } & $\mathrm{N}$ & 27 & 13 & 8 & 2 \\
\hline & $\%$ & $30,3 \%$ & $24,5 \%$ & $23,5 \%$ & $14,3 \%$ \\
\hline \multicolumn{6}{|l|}{ Type of surgery } \\
\hline Resection of primary tumor & $\%$ & $6 \%$ & $6 \%$ & $0 \%$ & $0 \%$ \\
\hline Lymph node resection & $\%$ & $11 \%$ & $7 \%$ & $1 \%$ & $1 \%$ \\
\hline All other visceral & $\%$ & $12 \%$ & $5 \%$ & $4 \%$ & $0 \%$ \\
\hline Brain metastases & $\%$ & $5 \%$ & $3 \%$ & $1 \%$ & $1 \%$ \\
\hline Isolated limb perfusion & $\%$ & $0 \%$ & $0 \%$ & $0 \%$ & $0 \%$ \\
\hline Biopsy & $\%$ & $6 \%$ & $3 \%$ & $1 \%$ & $0 \%$ \\
\hline Distant skin, subcutaneous or node & $\%$ & $5 \%$ & $3 \%$ & $1 \%$ & $0 \%$ \\
\hline Lung & $\%$ & $1 \%$ & $1 \%$ & $0 \%$ & $0 \%$ \\
\hline Total surgery cost per patient with any surgery (€ 2009) & Mean & 7.621 & 9.070 & 5.778 & 7.426 \\
\hline Total surgery cost per patient $(€ 2009)$ & Mean & 2.312 & 2.225 & 1.360 & 1.061 \\
\hline
\end{tabular}


Table 12 Summary statistics for surgery for patients with no response to systemic therapy

\begin{tabular}{|c|c|c|c|c|c|}
\hline & & Overall & First-line therapy & Second-line therapy & Third-line therapy \\
\hline $\mathrm{N}$ & & 119 & 94 & 78 & 27 \\
\hline \multirow[t]{2}{*}{ Patients with any surgery } & $\mathrm{N}$ & 23 & 23 & 10 & 3 \\
\hline & $\%$ & $19,3 \%$ & $24,5 \%$ & $12,8 \%$ & $11,1 \%$ \\
\hline \multicolumn{6}{|l|}{ Type of surgery } \\
\hline Resection of primary tumor & $\%$ & $3 \%$ & $3 \%$ & $0 \%$ & $0 \%$ \\
\hline Lymph node resection & $\%$ & $10 \%$ & $9 \%$ & $2 \%$ & $1 \%$ \\
\hline All other visceral & $\%$ & $10 \%$ & $7 \%$ & $3 \%$ & $3 \%$ \\
\hline Brain metastases & $\%$ & $4 \%$ & $2 \%$ & $2 \%$ & $0 \%$ \\
\hline Isolated limb perfusion & $\%$ & $0 \%$ & $0 \%$ & $0 \%$ & $0 \%$ \\
\hline Biopsy & $\%$ & $6 \%$ & $6 \%$ & $1 \%$ & $1 \%$ \\
\hline Distant skin, subcutaneous or node & $\%$ & $7 \%$ & $6 \%$ & $2 \%$ & $0 \%$ \\
\hline Lung & $\%$ & $0 \%$ & $0 \%$ & $0 \%$ & $0 \%$ \\
\hline Total surgery cost per patient with any surgery (€ 2009) & Mean & 7.119 & 4.841 & 5.583 & 7.780 \\
\hline Total surgery cost per patient (€ 2009) & Mean & 1.376 & 1.185 & 716 & 864 \\
\hline
\end{tabular}

Although the above mentioned limitations, this is the first study where the cost of treatment for a patient with advanced melanoma has been estimated in Italy. Even at the international level, few cost of illness studies can be found reporting such data. Some of such studies do analyse cost as a function of the illness stage; nevertheless, due to differences in methods, their results cannot be compared with the findings of the present study. Moreover, such studies are generally focused on the total cost charged to the national health system, from which they cannot derive a per patient cost based on of epidemiological information.

However, a study carried out in Spain reports cost data at patient level (referred to 2007) [21]. Based on a theoretical model, it concludes that higher costs are associated to patients with advanced melanoma. Only direct medical costs were considered, particularly hospitalization ones, broken down by four seriousness levels of the illness: detection, resection, surgical treatment of lymphatic spread, oncologic treatment of metastatic melanoma. As a first approximation, patients included in the fourth level might be considered homogeneous with those enrolled in the MELODY study. In the Spanish study two average per patient cost data (on yearly basis) are reported with reference to advanced melanoma: for patients with lymph node metastasis $(€ 6,457)$ and for patients with visceral metastasis $(€ 1,036)$. Size information of the two subset is not provided, so a weighted average cannot be calculated. But, assuming approximately equal sizes, an average value would result similar to that above reported for Italy $(€ 3,456)$.

For the sake of completeness it is worthwhile reporting the results from three further studies, though no per patient cost data are there provided. In the first study, which is referred to France, the yearly (2004) cost is estimated for the French hospital system to treat patients

Table 13 Summary costs per patient

\begin{tabular}{|c|c|c|c|c|c|}
\hline & $\begin{array}{l}\% \text { with any } \\
\text { utilization }\end{array}$ & $\begin{array}{l}\text { Mean cost } \\
\text { per patient with } \\
\text { non- zero utilization }(€)\end{array}$ & $\begin{array}{l}\text { Overall cost } \\
\text { per patient based } \\
\text { on mean }{ }^{(1)}(€)\end{array}$ & $\begin{array}{l}\text { Overall cost } \\
\text { per responder } \\
\text { based on mean }{ }^{(1),(2)}(€)\end{array}$ & $\begin{array}{l}\text { Overall cost } \\
\text { per non-responder } \\
\text { based on mean }{ }^{(1),(3)}(€)\end{array}$ \\
\hline Hospitalization & $9,8 \%$ & 25.400 & 2.481 & 4.524 & 882 \\
\hline Hospice & $5,6 \%$ & 3.300 & 184 & $184^{(4)}$ & $184^{(4)}$ \\
\hline Emergency room & $1,4 \%$ & 300 & 4 & $4^{(4)}$ & $4^{(4)}$ \\
\hline Outpatient & $40,5 \%$ & 70 & 28 & 33 & 22 \\
\hline Radiotherapy & $19,7 \%$ & 2.814 & 555 & 506 & 591 \\
\hline Transfusion & $3,8 \%$ & 300 & 12 & $12^{(4)}$ & $12^{(4)}$ \\
\hline Surgery & $24 \%$ & 7.390 & 1.776 & 2.312 & 1.376 \\
\hline Total & & & 5.0470 & 7.575 & 3.071 \\
\hline
\end{tabular}

(1) For the follow-up period (17,5 months on average). Patients with zero resource utilisation are included.

(2) For patients with any response to systemic therapy.

(3) For patients with no response to systemic therapy.

(4) Overall data as a proxy. 
with melanoma [22]. Such cost amounts to $€ 59$ million, 27 (45\%) of which are born for patients with metastasis. Main cost drivers are surgery (38\%), follow-up evaluations (20\%) and chemotherapy (17\%). Authors conclude that costs for treating melanoma represent less than $1 \%$ of total French hospital system costs for cancer.

In the second and third study, the cost of melanoma was evaluated within a larger research focused on costs of all kinds of skin tumours. In particular, in the second study [23] cost data (2003) are reported relative to the hospital system in Germany, where about 20\% of hospitalizations for skin tumours $(62,384)$ are related to patients with melanoma $(20,445)$, identified with ICD 10 code $\mathrm{C} 43$. For such patients, the total cost estimate vary depending on the resource evaluation method adopted: from $€ 59$ million (evaluation with DRG tariffs) to $€ 55$ million (evaluation with average cost per day stay). So, the average hospitalization cost per (C43) patient approximately ranges between $€ 2,900$ and $€ 2,700$.

In the third study cost data (2005) are reported for treating patients (here too identified with ICD 10 code C43) with skin tumours in Sweden [24]. The study, which estimated both direct and indirect costs, reports a total amount of $€ 142$ million, of which direct medical costs represent 56\%. Melanoma is associated to the highest financial burden ( $€ 80$ million, of which 22 for direct costs). Dividing such total direct cost by the number of recorded treatment cases, an average cost per case is obtained of about $€ 2,000$. Considering that for each patient more than one case on the average was recorded, also this data may be comparable with previously reported ones.

Before concluding, a recent review should be mentioned [25] where three cost-effectiveness studies and two cost-utility studies of chemotherapic treatment of metastatic melanoma were analysed. The authors conclude that the cost-effectiveness has not been widely demonstrated for treatment of metastatic melanoma and that a need exists for effective treatments that improve duration and quality of life.

As a conclusive remark, a message can be drawn from the present study: the cost for treating advanced melanoma is not particularly high (neither in Italy nor in other West European countries). In our opinion, this is mainly due to the fact that there are no effective treatmentsavailable, which can improve both duration and quality of life. Evidence of such opinion can be found in the low frequencies with which some resources are used, in particular hospitalization (less than 10\%), considering that patients are hospitalized mainly for being administered an antitumoral therapy. Further evidence is provided by the above mentioned review [25], showing the poor cost-effectiveness of the analyzed treatments. Also the French study [22] confirms the low financial impact of the advanced melanoma treatment (less than $1 \%$ of total French hospital system costs for cancer). A medical need does therefore exist (as pointed out in most studies here considered) of more research and development investments in new effective and safe pharmacological treatments.

\section{Endnotes}

${ }^{\text {a }}$ This is true for all the tables focused on response/nonresponse to therapy (i.e. tables regarding hospitalization, outpatient visits, radiotherapy, surgery), although it is most noticeable for hospitalization length of stay because this is an outcome that can be heavily influenced by a single patient with a long hospitalization. For example, if a patient had a very long hospitalization during first line therapy, and he did not respond to first-line therapy but did to a subsequent line of therapy, such hospitalization would be included in the Overall column in Table 4 (because the patient did respond to at least one line of therapy), and in the first-line column in Table 5 (because he did not respond to first-line therapy, which is when the hospitalization actually took place).

\section{Abbreviations \\ FDA: Food and Drug Administration; AJCC: American Joint Commission on Cancer; DRG: Diagnosis Related Groups; ATC: Anatomical Therapeutic Chemical; AE: Adverse events; ICD: International Classification of Diseases.}

\section{Competing Interest}

Dr. P. Ascierto is consultant for Bristol Myers Squibb, Merck Sharp and Dohme, Roche Genentch, was involved in Advisory Board for Bristol Myers Squibb, Merck Sharp and Dohme, Glaxo Smith Kline, Celgene, Amgen, Medimmune, Novartis, and has received honoraria from Bristol Myers Squibb, Merck Sharp and Dohme, Roche Genentch; MD A. Testori has received honoraria for participating to advisory boards to discuss treatment options in stage IV melanoma patients with pharm companies as BMS, Roche Amgen GSK Merk Celgene; Dr. P. Queirolo was involved in Advisory Board for BMS, Glaxo Smith, Roche Genetech.

\section{Authors' contribution}

All authors contributed to the design, analysis and interpretation of data; $\mathrm{MM}$ and $\mathrm{CL}$ were envolved in drafting the article. All authors revised the article and provided final approval.

\section{Aknowledgments}

Research support: This study was sponsored by Bristol-Myers Squibb.

\section{Author details}

${ }^{1}$ Medical Oncology and Immunotherapy, Azienda Ospedaliera Universitaria Senese, Istituto Toscano Tumori, Strada delle Scotte, 53100 Siena, Italy. ${ }^{2}$ Istituto Nazionale Tumori, Fondazione Pascale, Naples, Italy. ${ }^{3}$ Istituto Europeo di Oncologia, Milan, Italy. ${ }^{4}$ IRCCS - IRST, Meldola, Forli-Cesena, Italy. ${ }^{5}$ Istituto di Oncologia, Policlinico di Monza, Italy. ${ }^{6}$ Oncologia Medica A, Azienda Ospedaliera S. Martino-, Istituto Nazionale per la Ricerca sul Cancro IST, Genoa, Italy. ${ }^{7}$ Istituto Tumori Giovanni Paolo II, IRCCS, Bari, Italy. ${ }^{8}$ Oncologia Medica 1, AOU Pisana "Spedali Riuniti di Santa Chiara", Pisa, Italy. "Istituto Oncologico Veneto, IRCCS, Padova, Italy. ${ }^{10}$ Health Economics \& Outcome Research Unit, BMS Italy, Rome, Italy. ${ }^{11}$ Head Market Access \& External Affairs, Novartis Oncology, Amsterdam, Netherlands. ${ }^{12}$ Global Clinical Research Oncology, BMS Global, Wallingford, Oxfordshire, UK. ${ }^{13}$ Health Economist, Springer Healthcare, Milan, Italy.

Received: 23 July 2012 Accepted: 11 October 2012

Published: 1 November 2012 


\section{References}

1. Devries E, Bray I, Coebergh JW, et al: Changing epidemiology of malignant cutaneous melanoma in Europe 1953-1997. Int I Cancer 2003, 107:119-126.

2. Ferlay J, Autier P, Boniol M, et al: Estimates of the cancer incidence and mortality in Europe in 2006. Ann Oncol 2007, 18:581-592.

3. Lens MB, Dawes M: Global perspectives of contemporary epidemiological trends of cutaneous malignant melanoma. Br J Dermatology 2004, 150:179-185.

4. Amerio $P$, et al: Epidemiology and clinical and pathologic characteristics of cutaneous malignant melanoma in Abruzzo (Italy). Int I Dermatol 2009, 48(7):718-722.

5. Miller AJ, Mihm MC: Melanoma. N Engl J Med 2006, 355:51-65.

6. Thompson JF, Scolyer RA, Kefford RF: Cutaneous melanoma. Lancet 2005, 365:687-701.

7. Tsao H, Atkins MB, Sober AJ: Management of cutaneous melanoma. N Engl J Med 2004, 351:998-1012.

8. Smyth JF, Aamdal S, Awada A, et al: Phase II study of E7070 in patients with metastatic melanoma. Ann Oncol 2005, 16:158-161.

9. Eggermont AMM: Reaching first base in the treatment of metastatic melanoma. J Clin Oncol 2006, 24:4673-4674.

10. Roberts DLL, Anstey AV, Barlow RJ, et al: U.K. guidelines for the management of cutaneous melanoma. Br J. Dermatology 2002, 146:7-17.

11. Fabi A, Felici A, Metro $G$, et al: Brain metastases from solid tumors: disease outcome according to type of treatment and therapeutic resources of the treating center. J Exp Clin Cancer Res 2011, 30:10.

12. Balch CM, Buzaid AC, Soong SJ, et al: Final version of the american joint committee on cancer staging system for cutaneous melanoma. J Clin Oncol 2001, 19:3635-3648.

13. Ministero dell'Economia e Finanze: Libro verde sulla Spesa Pubblica. Roma; 2007.

14. Ministero della Salute: Hospice in Italia: prima rilevazione ufficiale, 2006. Milano: Medica Editoria e Diffusione Scientifica; 2007.

15. Ministero della Salute. Progetto Mattoni SSN. Pronto Soccorso e Sistema 118: Proposta metodologica per la valutazione dei costi dell'emergenza. Roma; 2007.

16. Ministero della Sanità: Prestazioni di assistenza ambulatoriale erogabill nell'ambito del Servizio Sanitario Nazionale e relative. Roma: Decreto Ministeriale; 1996.

17. Banca Dati Sanitaria Farmaceutica; VDA Net 2010 http://www.giofil.it (accessed Apr 19, 2011).

18. Conferenza delle Regioni e delle Province autonome: Tariffa unica convenzionale (TUC) per le prestazioni di assistenza ospedaliera. Regole e tariffe valide per l'anno 2009. Roma; 2010.

19. Testori A, Rutkowski P, Marsden J, et al: Surgery and radiotherapy in the treatment of cutaneous melanoma. Ann Oncol 2009, 20(Suppl 6):vi22-vi29.

20. Presidenza del Consiglio dei Ministri: Conferenza Stato Regioni; Seduta del 24 luglio 2003.

21. Almazàn-Fernàndez FM, Serrano-Ortega S, Moreno-Villalonga JJ: Descriptive study of the costs of diagnosis and treatment of cutaneous melanoma. Actas Dermosifiliogr 2009, 100:785-791.

22. Chevalier J, Bonastre J, Avril M-F: The economic burden of melanoma in France: assessing healthcare use in a hospital setting. Melanoma Res 2008, 18(1):40-46.

23. Stang A, Stausberg J, Boedeker W, Kerek-Bodden H, Jöckel K-H: Nationwide hospitalization costs of skin melanoma and non-melanoma skin cancer in Germany. JEADV 2008, 22:65-72.

24. Tinghög G, Carlsson P, Synnerstad I, Rosdhal I: Societal cost of skin cancer in Sweden 2005. Acta Dermo Venereol 2008, 88:467-473.

25. Cashin RP, Lui P, Machado M, Hemels MEH, Corey-Lisle PK, Einarson TR Advanced cutaneous malignant melanoma: a systematic review of economic and quality-of-life studies. Value Health 2008, 11(2):259-271.

doi:10.1186/1756-9966-31-91

Cite this article as: Maio et al:: The cost of unresectable stage III or stage IV melanoma in Italy. Journal of Experimental \& Clinical Cancer Research 2012 31:91

\section{Submit your next manuscript to BioMed Central and take full advantage of:}

- Convenient online submission

- Thorough peer review

- No space constraints or color figure charges

- Immediate publication on acceptance

- Inclusion in PubMed, CAS, Scopus and Google Scholar

- Research which is freely available for redistribution

Submit your manuscript at www.biomedcentral.com/submit
Biomed Central 